\title{
Nerve Growth Factor-Tyrosine Kinase A Pathway Is Involved in Thermoregulation and Adaptation to Stress: Studies on Patients with Hereditary Sensory and Autonomic Neuropathy Type IV
}

\author{
NETA LOEWENTHAL, JACOV LEVY, RUTH SCHREIBER, VERED PINSK, ZVI PERRY, \\ ZAMIR SHORER, AND ELI HERSHKOVITZ \\ Pediatric Department, Soroka Medical Center and Faculty of Health Sciences, Ben-Gurion University of \\ the Negev, Be'er Sheva, Israel
}

\begin{abstract}
Hereditary sensory and autonomic neuropathy type IV (HSAN IV) is caused by mutations in the tyrosin kinase A (TrkA) gene, encoding for the high-affinity receptor of nerve growth factor (NGF). The NGF-TrkA system is expressed in many endocrine glands. We hypothesized that HSAN IV represents a natural model for impaired NGF effect on the neuroendocrine system in humans. We have documented the clinical outcome of 31 HSAN IV patients in a single medical center, and investigated their basal endocrine system status. The endocrine system response to thirst was compared between six patients and six healthy children. High rates of mortality (22\%) and severe morbidity $(30 \%)$ have been found in HSAN IV patients. Hypothermia was noted in $40 \%$ of the patients and unexplained fever was observed in $56 \%$. Subnormal adrenal function was demonstrated in six $(30 \%)$ of the patients studied. Furthermore, we found lower plasma norepinephrine (NE) levels in six HSAN IV patients compared with a control group after the thirst test. Our
\end{abstract}

\section{ABSTRACT}

findings emphasize the importance of NGF-TrkA pathway in the physiology of the neuroendocrine system and its response to stress. Inadequate response to stress might contribute to the observed significant mortality, morbidity, and temperature instability in HSAN IV patients. (Pediatr Res 57: 587-590, 2005)
HPA axis, hypothalamic-pituitary-adrention IV
IGFBP3, IGF binding protein 3
LDAT, low-dose ACTH test
NE, norepinephrine
NGF, nerve growth factor
SDS, standard deviation score
TrkA, tyrosine kinase A

HSAN IV, hereditary sensory and autonomic neuropathy type
HSAN IV (OMIM 256800), also known as congenital insensitivity to pain with anhidrosis, belongs to a group of rare autosomal recessive peripheral sensory neuropathies. It involves the loss of pain sensation, which leads to fractures and skin lacerations often evolving into deep wounds, with complications such as osteomyelitis, septic arthritis, and Charcot joints. Moderate-to-severe mental retardation is present in most of the patients, and this combination of insensitivity to pain and mental retardation seems to lead to self-mutilation of the tongue and fingertips with frequent autoamputations. Anhidrosis, another prominent component of the disorder, is often associated with recurrent episodes of unexplained fever, which can be fatal (1-3). Typical histologic findings include a com-

Received February 19, 2004; accepted August 12, 2004.

Correspondence: Eli Hershkovitz, M.D., Pediatric Department, Soroka Medical, Center, POB 151, Beer Sheva 84101, Israel; e-mail: elih@bgumail.bgu.ac.il

DOI: 10.1203/01.PDR.0000155941.37155.41 plete absence of nonmyelinated and small myelinated nerve fibers in the dorsal root ganglia and normal number and structure of the sweat glands, but lack of the innervations of small diameters neurons (4).

HSAN IV was previously diagnosed only by characteristic clinical findings. However, recently, mutations in the TrkA gene, encoding the high-affinity receptor for NGF, have been implicated in the pathogenesis of HSAN IV (5-8). NGF induces neural outgrowth and promotes survival of embryonic sensory and sympathetic neurons $(9,10)$. In addition to its trophic function, NGF seems to be involved in a phenomena related to HPA axis activity (11-14).

In view of recent advances in the understanding of the pathophysiology of HSAN IV, we have conducted a study to evaluate the basic endocrine status and the adaptation of patients with HSAN IV to stress stimuli by assessing the integrity of the HPA axis and the catecholamine response during thirst. 


\section{SUBJECTS AND METHODS}

Subjects. The clinical diagnosis of HSAN IV in the studied patients was confirmed by genetic analysis of the TrkA gene. All patients carried a homozygous mutation, 1926-ins-T, as previously described (8). The patients were followed in the ambulatory pediatric department at Soroka Medical Center. Our study was approved by the local ethics committee. Signed informed consent was obtained from the patients' parents.

The medical charts of 31 HSAN IV patients were reviewed. Clinical data and growth charts were obtained from the patients' medical records. All the patients were Israeli Bedouins with an average age of 5.2 y $(0.25-12$ y). Seventeen patients $(53 \%)$ were male and $14(47 \%)$ were female. Twenty-two patients $(71 \%)$ were available for clinical follow-up and testing during the study period.

We assessed the autonomic nervous system and looked for signs of endocrine dysfunction, such as fever (body temperature $>38.2^{\circ} \mathrm{C}$ ), hypothermia (body temperature $<35^{\circ} \mathrm{C}$ ), cardiac arrhythmias, hyper- or hypotension, and electrolyte imbalance.

Endocrine evaluation. Blood for baseline samples of serum TSH, free T4, prolactin, cortisol, IGF-I, and IGFBP3 were drawn between 0900 and $1200 \mathrm{~h}$

Patients with random cortisol levels $<276 \mathrm{nmol} / \mathrm{L}$ underwent LDAT Plasma cortisol levels were measured $30 \mathrm{~min}$ after Synacten administration (1 $\mu \mathrm{g}$ ). Plasma cortisol level of $600 \mathrm{nmol} / \mathrm{L}$ or higher was considered to indicate an intact HPA axis (15).

Six patients with HSAN IV agreed to participate in a 7-h thirst test, performed to evaluate their response to stress. A control group, consisting of six children, was referred for fasting or thirst test as part of the investigations for suspected hypoglycemia or diabetes insipidus, respectively. Their thirst test results were found to be normal (Table 1). Thirst was chosen as an appropriate stress stimulus because of the tendency of HSAN IV patients to develop unexplained fever in the hot and dry weather, which is common in our geographic area. Blood pressure, heart rate, respiratory rate, body temperature, body weight, and urine specific gravity were measured hourly. Ambient room temperature was kept between 20 and $22^{\circ} \mathrm{C}$. The test's participants were awake for most of the thirst period and stayed with their parents in a small room. Blood samples were taken via an indwelling intravenous catheter. The test was terminated once one of the following was observed: weight loss of more than $7 \%$, body temperature rise to $>38.2^{\circ} \mathrm{C}$, or urine specific gravity increase to 1025. Blood samples for $17 \mathrm{OH}$-progesterone, cortisol, and NE were taken at baseline and after $7 \mathrm{~h}$ of fasting.

Hormones were measured at the Soroka Medical Center's endocrine laboratory. Serum IGF-I levels were measured by IMMULITE 2000 Analyzer (Diagnostic Products, Los Angeles, CA) using IMMULITE 2000 IGF-I assay (Diagnostic Products). Serum IGFBP3 levels were measured by Immulite 2000 IGFBP3 assay (Diagnostic Products). Serum levels of cortisol, free T4, and TSH were measured by specific ADVIA Centaur assays (Bayer Diagnostics, Tarrytown, NY). Serum 17OH-progesterone was measured by a RIA kit (Schering-CIS bio international, Yvette Cedex, France). Plasma samples for NE were kept at $-20^{\circ} \mathrm{C}$ and were measured simultaneously by HPLC.

Statistical analysis. Weight, height, growth rate, IGF-I, and IGFBP3 measurements were expressed as SDS. The proportions of the lowest values ( $Z$ scores $<-2$ ) were calculated in our patients and compared with the expected proportions of these values in the general population $(\sim 3 \%)$. Two nonparametric tests were used to compare the results of the thirst study. MannWhitney test was used to compare the changes of the measured parameters between the two different groups. Wilcoxon test was used to compare the change of the parameters before and after the test in the patients and in the control group. The statistical analysis was performed using SPSS software (version 10.1, SPSS Inc., Chicago, IL).

\section{RESULTS}

Morbidity and mortality in HSAN IV patients. Seven out of 31 patients $(23 \%)$ died. The age of death ranged between $40 \mathrm{~d}$ and 7 y. Five patients (16\%) died before their first birthday. Two patients (6.5\%) were 7 y old at death.

Table 1. Demographic characteristics of the thirst test participants

\begin{tabular}{lcc}
\hline & HSAN IV $(n=6)$ & Controls $(n=6)$ \\
\hline Age $(\mathrm{mo})$ & $22.5 \pm 20$ & $18.5 \pm 16$ \\
Sex & 6 males & 2 males $/ 4$ females \\
Ethnic origin & 6 Bedouins & 4 Jews, 2 Bedouins \\
\hline
\end{tabular}

The causes of death were infectious diseases, cardiac arrest, or unknown causes. Nine of the patients (33\%) were admitted to the pediatric intensive care unit due to neonatal hypothermia, septic shock, and cardiac arrest. Four of these patients died.

Anesthetic complications. Twenty-two of the patients (73\%) had at least one surgical procedure under general anesthesia. Most of the patients had more than one surgical procedure. These procedures included limb amputations, drainage of deep soft tissues abscesses or chronic osteomyelitis, teeth extraction and ophthalmic surgeries. Four out of 22 patients $(18 \%)$ had major complications, including hypothermia (two patients), cardiac arrest, and hypotension after surgery.

Hyperthermia was not evident in any of the patients during or after anesthesia. After our adoption of an anesthetic policy in HSAN IV patients, which included intensive cardiopulmonary and body temperature monitoring of the patients, no adverse anesthetic events have been recorded.

Vital signs. Hypothermia was found in 12 of our patients (39\%). Ten patients showed neonatal hypothermia and, in seven (70\%), hypothermia had been recorded during a proven bacterial infection. Asymptomatic hypothermia was noted in 7 out of 17 of the HSAN IV patients (40\%) during their routine follow-up visits. Unexplained fever was found in 17 patients $(54 \%)$.

Blood pressure and pulse rate measurements of patients were appropriate for their age and sex during their regular clinic visits.

Growth. Weight, height, and growth rate were recorded in 21 patients $(68 \%)$. SDS of these parameters were calculated. We found that 9/21 HSAN IV patients (41\%) had height SDS below $-2(\mathrm{Z}=7.9, n>1.96, p<0.01)$ and $6 / 21(28 \%)$ had SDS for weight below $-2(\mathrm{Z}=4.96, n>1.96, p<0.01)$. Growth rate was slower in patients with HSAN IV. The prevalence of growth rate SDS below -1 was 11/18 (60\%) (Z $=10, n>2.38, p<0.01$.

Basal endocrine studies. Basal glucose, electrolytes, thyroxine, TSH, and prolactin plasma levels were studied in 20 HSAN IV patients and were found to be within normal range, except in one patient with primary hypothyroidism. This patient had normal thyroid function at the time of neonatal screening (data not shown).

SDS for mean plasma IGF-I levels were $-1 \pm 0.6$. Only one patient $(5 \%)$ had a SDS for plasma IGF-I levels below -2 (NS). SDS for mean plasma IGFBP3 levels were $-1.3 \pm 0.8$, and four patients (20\%) had plasma IGFBP3 SDS below -2 (Z $=3.0, n>1.96, p<0.01)$.

Adrenal function. Eleven patients (55\%) had random plasma cortisol levels $<276 \mathrm{nmol} / \mathrm{L}$. LDAT had been performed in eight of these patients $(73 \%)$. Subnormal response (i.e. cortisol $<600 \mathrm{nmol} / \mathrm{L}$ ) was present in six patients, including two patients whose cortisol response was $<400 \mathrm{nmol} / \mathrm{L}$. Thus, at least $30 \%(6 / 20)$ of the patients tested had evidence of HPA axis dysfunction.

Thirst test results. The demographic and clinical background of six HSAN IV patients and six control participants in the thirst test are described in Table 1. The test was prematurely terminated in three of the HSAN IV patients (50\%) due 
to fever rising above $39.3^{\circ} \mathrm{C}$ (two patients) and irritability with hypotension in one patient. In a single control subject, the test was terminated after maximal urinary specific gravity was achieved.

There were no differences in average blood pressure, pulse, respiratory rates, and urine osmolalities before and after the test in both study groups (data not shown).

We found that the patients' body temperature had increased during the test by $1.2 \pm 1.4^{\circ} \mathrm{C}$ in comparison to $-0.1 \pm 0.5^{\circ} \mathrm{C}$ in the control group $(p=0.041)$.

The endocrine test results before and after the thirst test are shown in Table 2. Plasma cortisol levels were similar in both groups before and after the thirst test. Cortisol levels increased in the HSAN IV group from $205 \pm 74.5 \mathrm{nmol} / \mathrm{L}$ to $380 \pm 184$ $\mathrm{nmol} / \mathrm{L}$ after the test $(p=0.028)$.

$17 \mathrm{OH}$-progesterone levels increased significantly in both groups after the tests. Plasma NE concentration was lower in the HSAN IV patients at the end of the thirst test, in comparison to the control $(0.25 \pm 0.14 \mathrm{nmol} / \mathrm{L}$ versus $1.07 \pm 0.71$ $\mathrm{nmol} / \mathrm{L}, p=0.025)$.

No significant correlations were found between the levels of $\mathrm{NE}$ and blood pressure, heart rate, and respiratory rate.

\section{DISCUSSION}

Unexplained fever is a well-recognized clinical feature of HSAN IV patients $(1,3,16)$. Therefore, the high prevalence of fever without any signs of infection among our patients is not surprising. TrkA is expressed in the hypothalamus, where the preoptic region plays a crucial role in thermoregulation (1720). Absence or decreased TrkA expression at this critical area may explain the observed hyperthermia in HSAN IV. Anhidrosis, caused by deficient innervation of the sweat glands, is also an important factor in the development of fever (16). Our patients' inability to adequately regulate their body temperature has a particular clinical relevance because they live in a desert terrain.

The unexpected finding of incidental hypothermia in $40 \%$ of the patients is intriguing, because this sign had not been previously documented in HSAN IV, except when these patients are exposed to extreme cold (21). We also found that hypothermia was common during the neonatal period, when it was mainly associated with bacterial infections. Sympathetic

Table 2. Endocrine results: basal and post thirst test (mean $\pm S D$ )

\begin{tabular}{lcc}
\hline & HSAN IV & Control \\
\hline Basal cortisol (nmol/L) & $205 \pm 74^{*}$ & $275 \pm 413$ \\
Post-test cortisol (nmol/L) & $378 \pm 184^{*}$ & $303 \pm 137.5$ \\
Basal 17OH progesterone (nmol/L) & $0.24 \pm 0.21^{* *}$ & $0.3 \pm 0.27 \Phi$ \\
Post-test 17OH progesterone (nmol/L) & $0.69 \pm 0.33^{* *}$ & $2 \pm 1.7 \mathrm{I}$ \\
Basal NE (nmol/L) & $0.2 \pm 0.11$ & $0.93 \pm 0.89$ \\
Post-test NE (nmol/L) & $0.25 \pm 0.14 \S$ & $1.07 \pm 0.71 \S$ \\
\hline
\end{tabular}

* Comparison between the average plasma cortisol level before and after the test $(p=0.028)$.

** Comparison between the $17 \mathrm{OH}$ progesterone level before and after the test in the HSAN IV patients $(p=0.043)$.

If Comparison between the $17 \mathrm{OH}$ progesterone level before and after the test in the control group $(p=0.046)$.

$\S$ Comparison between the plasma NE level in the end of the test between the two groups $(p=0.025)$. response to cold exposure determines the body's thermoregulatory function by dermal vasoconstriction, mediated by skin $\mathrm{NE}$ activity (22). Absence of sympathetic skin response has recently been demonstrated in patients with HSAN IV (23). Abnormal hypothalamic-mediated thermoregulation combined with a decrease in skin sympathetic activity may explain the high incidence of hypothermic events in our patients.

Our patients had blood pressure and heart rate values that were within the normal range for their age group during routine clinic visits. The retrospective nature of our study precluded a more thorough search for minor changes of pulse and blood pressure during planned study visits.

The NGF-TrkA system is expressed in many endocrine glands such as the hypothalamus, ovary, adrenal, and thyroid glands $(17,24,25)$. It has been noted that NGF has an important role in somatotroph cell differentiation $(26,27)$. Dysfunction of the GH-IGF-I axis could not explain the growth retardation in most of our patients, because plasma IGF-I and IGFBP3 levels were within the normal range in all the patients, except for one and four patients, respectively. However, formal GH stimulation tests have not been performed in these patients and normal IGF-I and IGFBP3 plasma levels do not unequivocally rule out GH deficiency $(28,29)$.

Rat embryos treated with anti-NGF receptor antibody had small thyroid size (30). We found only one patient with primary acquired hypothyroidism in our cohort of HSAN IV patients. Alternative compensating mechanisms and decreased physiologic significance of NGF or TrkA as a mediator of NGF effect in human thyroid development may explain the discrepancy between humans and rats in respect to thyroid development.

NGF increases HPA activity in rats (12,31). Daily administration of highly purified NGF resulted in a considerable increase in the adrenal gland volume (14).

We found that at least $30 \%$ of the patients had subnormal cortisol response to LDAT. LDAT is a useful, safe, and inexpensive tool for the initial assessment of HPA function in patients with hypothalamic-pituitary disease (15). LDAT was equivalent to both the standard ACTH test and to insulininduced hypoglycemia in detecting HPA insufficiency in children with idiopathic multiple pituitary hormone deficiencies (32). It has high diagnostic sensitivity and specificity for primary adrenal insufficiency and can accurately identify subjects with preclinical adrenal dysfunction (33). Moreover, the performance characteristics of both high-dose $(250 \mu \mathrm{g})$ and low-dose $(1 \mu \mathrm{g})$ ACTH stimulation tests are similar for diagnosing secondary adrenal insufficiency (34). We assume that the subnormal response to LDAT in some of the HSAN IV patients may be of clinical significance during severe stress. Regarding the grave consequences of adrenal crisis, we recommend preventive hydrocortisone therapy given to a patient with HSAN IV during of life-threatening episodes (i.e. major surgery, severe trauma, sepsis).

It has been recently reported that stress induces secretion of NGF in humans and could elevate the expression of TrkA (35).

We performed a controlled thirst test, to assess our patients' response to clinically relevant stress. Our findings of elevated plasma 17OH-progesterone levels in the patients and in the control group during the thirst test suggest that the test was 
indeed a stressful procedure. We found significantly low NE levels in the patients compared with controls after the test. Low $\mathrm{NE}$ levels were also found in one of our patients during a major surgical procedure and in another patient during an episode of respiratory failure. Our results concur with previously reported low urinary and plasma catecholamine levels following general anesthesia in a small number of HSAN IV patients, compared with healthy controls (36).

These findings of low NE plasma levels in HSAN IV patients during general anesthesia may explain the risk of these patients developing abnormal body temperature and hypotension during the procedure.

In conclusion, our study demonstrates significant mortality and morbidity associated with impaired regulation of body temperature, and abnormal function of the endocrine system in HSAN IV patients. There is a dire need for further studies to understand the clinical importance of NGF, its high-affinity receptor TrkA, and its effects on body temperature control and the adaptation of the endocrine system to stress.

\section{REFERENCES}

1. Online Mendelian Inheritance in Man (OMIM), No. 256800. Available at http:// www.ncbi.nlm.nih.gov/entrez/dispomim.cgi?id $=256800$

2. Langer J, Goebel HH, Veit S 1981 Eccrine sweat glands are not innervated in hereditary sensory neuropathy type IV. An electron-microscope study. Acta Neuropathol (Berl) 54:199-202

3. Rosemberg S, Marie SK, Kliemann S 1994 Congenital insensitivity to pain with anhidrosis (hereditary sensory and autonomic neuropathy type IV). Pediatr Neurol 11:50-56

4. Goebel HH, Veit S, Dyck PJ 1980 Confirmation of virtual unmyelinated fiber absence in hereditary sensory neuropathy type IV. J Neuropathol Exp Neurol 39:670-675

5. Indo Y, Tsuruta M, Hayashida Y, Karim MA, Ohta K, Kawano T, Mitsubuchi H, Tonoki H, Awaya Y, Matsuda I 1996 Mutations in the TRKA/NGF receptor gene in patients with congenital insensitivity to pain with anhidrosis. Nat Genet 13:485-488

6. Mardy S, Miura Y, Endo F, Matsuda I, Sztriha L, Frossard P, Moosa A, Ismail EA, Macaya A, Andria G, Toscano E, Gibson W, Graham GE, Indo Y 1999 Congenital insensitivity to pain with anhidrosis: novel mutations in the TRKA (NTRK1) gene encoding a high-affinity receptor for nerve growth factor. Am J Hum Genet 64:15701579

7. Greco A, Villa R, Tubino B, Romano L, Penso D, Pierotti MA 1999 A novel NTRK1 mutation associated with congenital insensitivity to pain with anhidrosis. Am J Hum Genet 64:1207-1210

8. Shatzky S, Moses S, Levy J, Pinsk V, Hershkovitz E, Herzog L, Shorer Z, Luder A, Parvari R 2000 Congenital insensitivity to pain with anhidrosis (CIPA) in IsraeliBedouins: genetic heterogeneity, novel mutations in the TRKA/NGF receptor gene, clinical findings, and results of nerve conduction studies. Am J Med Genet 92:353360

9. Levi-Montalcini R 1987 The nerve growth factor 35 years later. Science 237:11541162

10. Korsching S 1993 The neurotrophic factor concept: a reexamination. J Neurosci 13:2739-2748

11. Ojeda SR, Hill DF, Katz KH 1991 The genes encoding nerve growth factor and its receptor are expressed in the developing female rat hypothalamus. Brain Res Mol Brain Res 9:47-55

12. Spillantini MG, Aloe L, Alleva E, De Simone R, Goedert M, Levi-Montalcini R 1989 Nerve growth factor mRNA and protein increase in hypothalamus in a mouse model of aggression. Proc Natl Acad Sci U S A 86:8555-8559

13. Aloe L, Alleva E, De Simone R 1990 Changes of NGF level in mouse hypothalamus following intermale aggressive behaviour: biological and immunohistochemical evidence. Behav Brain Res 39:53-61
14. Aloe L, Alleva E, Bohm A, Levi-Montalcini R 1986 Aggressive behavior induces release of nerve growth factor from mouse salivary gland into the bloodstream. Proc Natl Acad Sci U S A 83:6184-6187

15. Forest MG 2003 Adrenal function tests. In: Ranke MB (ed) Diagnostics of Endocrine Function in Children and Adolescents. Karger, Basel, Switzerland, pp 372-342

16. Ismail EA, AL-Shammari N, Anim JT, Moosa A 1998 Congenital insensitivity to pain and anhidrosis: lack of eccrine sweat gland innervation confirmed. J Child Neurol 13:243-246

17. Miranda RC, Sohrabji F, Toran-Allerand CD 1993 Neuronal colocalization of mRNAs for neurotrophins and their receptors in the developing central nervous system suggests a potential for autocrine interactions. Proc Natl Acad Sci U S A 90:64396443

18. Sobreviela T, Clary DO, Reichardt LF, Brandabur MM, Kordower JH, Mufson EJ 1994 TrkA-immunoreactive profiles in the central nervous system: colocalization with neurons containing p75 nerve growth factor receptor, choline acetyltransferase, and serotonin. J Comp Neurol 350:587-611

19. Cirulli F, Shooter EM, Levine S 1997 Developmental expression of the NGF receptor p140trk in the septohippocampal system of the rat: a quantitative analysis. Int J Dev Neurosci 15:901-909

20. Boulant JA 2000 Role of the preoptic-anterior hypothalamus in thermoregulation and fever. Clin Infect Dis 31:S157-S161

21. Indo Y 2002 Genetics of congenital insensitivity to pain with anhidrosis (CIPA) or hereditary sensory and autonomic neuropathy type IV. Clinical, biological and molecular aspects of mutations in TRKA(NTRK1) gene encoding the receptor tyrosine kinase for nerve growth factor. Clin Auton Res 12:I20-I32

22. Sawasaki N, Iwase S, Mano T 2001 Effect of skin sympathetic response to local or systemic cold exposure on thermoregulatory functions in humans. Auton Neurosci 87:274-281

23. Shorer Z, Moses SW, Hershkovitz E, Pinsk V, Levy J 2001 Neurophysiologic studies in congenital insensitivity to pain with anhidrosis. Pediatr Neurol 25:397-400

24. Dissen GA, Romero C, Hirshfield AN, Ojeda SR 2001 Nerve growth factor is required for early follicular development in the mammalian ovary. Endocrinology 142:2078-2086

25. Schober A, Minichiello L, Keller M, Huber K, Layer PG, Roig-Lopez JL, GarciaArraras JE, Klein R, Unsicker K 1997 Reduced acetylcholinesterase (AChE) activity in adrenal medulla and loss of sympathetic preganglionic neurons in TrkA-deficient, but not TrkB-deficient, mice. J Neurosci 17:891-903

26. Lahtinen T, Soinila S, Lakshmanan J 1989 Biological demonstration of nerve growth factor in the rat pituitary gland. Neuroscience 30:165-170

27. Missale C, Boroni F, Sigala S, Zanellato A, Dal Toso R, Balsari A, Spano P 1994 Nerve growth factor directs differentiation of the bipotential cell line GH-3 into the mammotroph phenotype. Endocrinology 135:290-298

28. Blum WF, Schweizer R 2003 Insulin-like growth factors and their binding proteins. In: Ranke MB (ed) Diagnostics of Endocrine Function in Children and Adolescents Karger, Basel, Switzerland, pp 166-199

29. Boquete HR, Sobrado PG, Fideleff HL, Sequera AM, Giaccio AV, Suarez MG, Ruibal GF, Miras M 2003 Evaluation of diagnostic accuracy of insulin-like growth factor (IGF)-I and IGF-binding protein-3 in growth hormone-deficient children and adults using ROC plot analysis. J Clin Endocrinol Metab 88:4702-4708

30. Aloe L, Cozzari C, Calissano P, Levi-Montalcini R 1981 Somatic and behavioral postnatal effects of fetal injections of nerve growth factor antibodies in the rat. Nature 291:413-415

31. Scaccianoce S, Cigliana G, Nicolai R, Muscolo LA, Porcu A, Navarra D, Perez-Polo JR, Angelucci L 1993 Hypothalamic involvement in the activation of the pituitaryadrenocortical axis by nerve growth factor. Neuroendocrinology 58:202-209

32. Weintrob N, Sprecher E, Josefsberg Z, Weininger C, Aurbach-Klipper Y, Lazard D, Karp M, Pertzelan A 1998 Standard and low-dose short adrenocorticotropin test compared with insulin-induced hypoglycemia for assessment of the hypothalamicpituitary-adrenal axis in children with idiopathic multiple pituitary hormone deficiencies. J Clin Endocrinol Metab 83:88-92

33. Laureti S, Arvat E, Candeloro P, Di Vito L, Ghigo E, Santeusanio F, Falorni A 2000 Low dose (1 microg) ACTH test in the evaluation of adrenal dysfunction in pre-clinical Addison's disease. Clin Endocrinol (Oxf) 53:107-115

34. Dorin RI, Qualls CR, Crapo LM 2003 Diagnosis of adrenal insufficiency. Ann Intern Med 139:194-204

35. Aloe L, Bracci-Laudiero L, Alleva E, Lambiase A, Micera A, Tirassa P 1994 Emotional stress induced by parachute jumping enhances blood nerve growth factor levels and the distribution of nerve growth factor receptors in lymphocytes. Proc Natl Acad Sci U S A 91:10440-10444

36. Daniel A, Shekim WO, Koresko RL, Dekirmenjian H 1980 Congenital sensory neuropathy with anhidrosis - a case report and investigation of autonomic nervous system abnormalities. J Dev Behav Pediatr 1:49-53 